\title{
The Acceptance Model of a National e-Payment in Thailand: Conceptual Framework
}

\author{
Patawee Chaluay ${ }^{1+}$, Singha Chaveesuk ${ }^{2}$ and Natapon Pantuwong ${ }^{3}$ \\ ${ }^{1,3}$ Faculty of Information Technology, King Mongkut's Institute of Technology Ladkrabang, \\ Bangkok, Thailand \\ ${ }^{2}$ Faculty Administration and Management, King Mongkut's Institute of Technology Ladkrabang, \\ Bangkok, Thailand
}

\begin{abstract}
The rapid growth of technology allows people to connect easier also through electronic commerce (e-Commerce). E-Commerce provides a great potential to support the user for trading in products or services with computer networks. Electronic payment (e-Payment) was developed to facilitate e-Commerce transactions. In recent years, the government has been trying to push a national e-Payment system in Thailand to aid economic development. This research will investigate the user's willingness to use a national e-Payment system in Thailand. The proposed model was developed by integrating the unified theory of acceptance and use of technology (UTAUT) with the task technology fit model (TTF) and Initial trust model (ITM). The contribution of this model will be used to examine the acceptance potential of the national e-payment user in Thailand.
\end{abstract}

Keywords: national e-Payment, UTAUT, TTF, ITM

\section{Introduction}

E-payment is a process of e-Commerce that includes electronic transactions in the purchase, sale or provision of services via the Internet system [1]. A common type of e-Payment is the operational network that links bank accounts and provides for monetary exchange using bank deposits [2]. Currently an efficient national e-payment reduces the cost of operations and it's easy to manage transactions of the interbank, money, and capital markets. A weak payment system may severely drag on the stability and developmental capacity of a national economy [3]. This means that many countries have begun to implement initiatives and policies to promote e-payment for economic development.

National e-Payment in Thailand is an electronic payment system the government is trying to push. This system supports electronic payment standards consistent with the use of technology, especially the Internet and mobile phones and the technology to be used to benefit the overall economy. The government through the Ministry of Finance has initiated the National e-Payment system since 2015 and over the past year.

However the acceptance of a national e-payment user in Thailand is still unclear. The focus on user perception of the technology may not be enough because in terms of the development of e-Commerce, security is considered the main factor that will affect internet users willingness to use online transactions. Many consumers are not willing to use online transactions as they are concerned about the security risks with the Internet [5]. In other words, when tasks become more financially complex, technologies will struggle to meet task demands [6]. This risk could affect user's acceptance.

\footnotetext{
+ Corresponding author. Tel.: +66862153349

E-mail address: Patawee.c@chandra.ac.th
} 
In this study, the Unified Theory of Acceptance and use of Technology (UTAUT) is used to explore the factors that influence people to accept national e-payment in Thailand. Integration with Task technology fit model (TTF) and Initial trust model (ITM) explains the variance of user acceptance.

\section{Theoretical foundation}

The users' technology acceptance has been studied in various ways. Many researchers have published various theories that could be used to explain the acceptance of information technology. The most popular theories include the technology acceptance model (TAM) [7] and the unified theory of acceptance and use of technology (UTAUT) [8].

In terms of TAM, Jokonya [9] used TAM to validate information technology adoption process in organizations. Lee Chang et al. [10] used TAM to explore 3D bio-printing technology in medical treatment adoption in Taiwan. Alloghani et al. [11] used TAM to study the use of m-health services among health related users in UAE. Chiang Lin et al. [12] used TAM to explain student behavior in accepting the blackboard learning system and Shaffie et al. [13] used TAM to study user's acceptance and perception towards campus management system (CMS).

In terms of UTAUT, Hongxia et al. [14] suggested that the UTAUT model is applicable to find drivers and barriers in the acceptance of mobile payment in China. Yin et al. [15] used the UTAUT model to study user's online payment behavior of tourism websites. Chin Yu et al. [16] used a modified UTAUT model to study older user's acceptance of smart card payment systems. Foon et al. [17] used UTAUT model to study the adoption of internet banking in Kuala Lumpur and Jarvinen et al. [18] used UTAUT model to examine the consumer acceptance and use of instagram application.

This research uses the UTAUT model as a base theory to explore the acceptance of national e-payment by users in Thailand since the users differ in terms of the diversity of personal factors that are applicable for factors of the UTAUT model such as performance expectancy (PE), efforts expectancy (EE), social influence (SI) and facilitating conditions (FC). On the other hand, TAM's applicability for users is not different in terms of the diversity of personal factors such as users in the same company, department and organization.

\subsection{Unified theory of acceptance and use of technology}

The Unified Theory of Acceptance and Use of Technology (UTAUT) was proposed by Venkatesh et al. in 2003. UTAUT integrates eight theories of information technology acceptance and consists of four determinants which are performance expectancy (PE), efforts expectancy (EE), social influence (SI) and facilitating conditions (FC). In addition, gender, age, experience and voluntariness of use are moderating variables [8]. The explanatory power of this model has reached $70 \%$ which is more than the other models proposed in the past.

The UTAUT model is frequently accepted not only in the national e-Payment acceptance research as mentioned above, but also in the acceptance and use of other information systems such as online payment, mobile payment, internet banking, mobile banking, and so on.

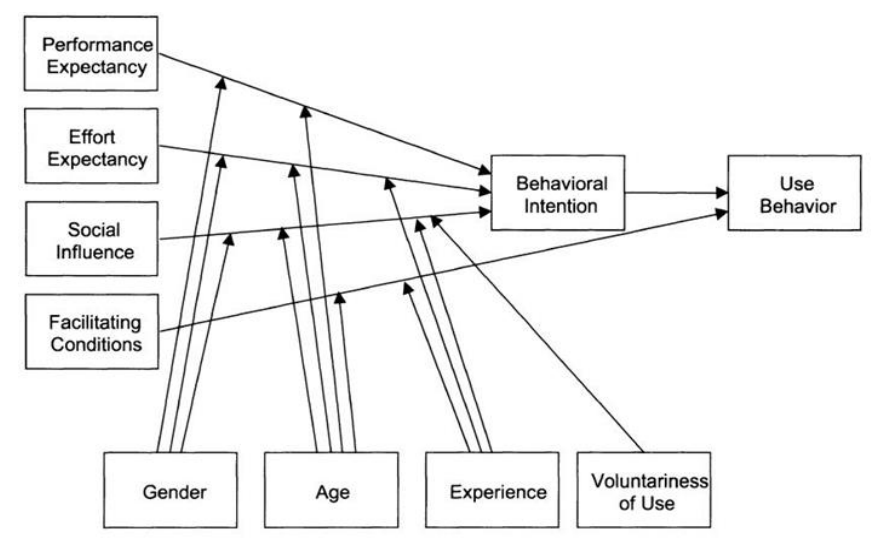

Fig. 1: UTAUT Model 


\subsection{Task technology fit}

The task technology fit model (TTF) argues that a user will only adopt an information technology when it fits his/her tasks at hand and improves his/her performance [19]. It is possible that even if the user has a high level of technological knowledge that the technology will not be used if they think that this technology is not suited to their tasks and can't improve their performance/productivity. [20]. TTF model is predicted by two technological aspects. These include technology characteristics (TC) and task characteristics (TAC).

Zhou et al. [21] used an integrated TTF and UTAUT to explain mobile banking user adoption. Dahghan et al. [22] studied the acceptance of mobile tourism using an integrated TTF and UTAUT model. Lee et al. [23] used a modified TTF model to explore the adoption of m-Commerce in the insurance industry.

\subsection{Initial trust}

Initial trust is the willingness of an individual to take risks to meet the demand without experience or reliable information [24]. Trust is an analysis that is linked to various services and is an important factor that has contributed to acceptance [25]. Hence, trust is an important factor to analyze.

Kim et al. [26] used the initial trust model (ITM) to study the relationship between initial trust in mobile banking and usage intentions as regards mobile banking. Gu et al. [27] used the initial trust model (ITM) to explore the effect of permission notice on users' initial trust for an application store in China. Susanto et al. [28] studied determinants of initial trust formation in electronic commerce acceptance in Indonesia.

According to an integrated UTAUT, TTF and ITM models have been used in several studies. Oliveira et al. [29] used an integrated UTAUT, TTF and ITM model to understand mobile banking adoption in a study conducted in Portugal. The result showed that the most important constructs explaining mobile banking adoption are behavioral intention (BI), facilitating conditions (FC), task technology fit (TTF), technology characteristic (TC), performance expectancy (PE) and initial trust (IT). Afshan et al. [30] studied the acceptance of a mobile banking framework in Pakistan with an integrated of UTAUT, TTF and ITM model. The study reveals the significance of task characteristics (TAC) and technology characteristics (TC) in facilitating task technology fit (TTF). Initial trust (IT) is also found to be facilitated by structural assurance (SA) and familiarity with bank (FB). The empirical findings also support the significant association of task technology fit (TTF), initial trust (IT) and facilitating condition (FC) with intention to accept mobile banking. This means that an integration of UTAUT, TTF and ITM present a holistic approach for future studies on the acceptance of new technology [29].

\section{Conceptual Framework and Hypothesis Development}

In order to study the factors that affect user's intention of national e-Payment in Thailand, this research will establish the proposed model based on UTAUT theory. Although UTAUT model proposed in the background of organizational adoption has relatively good explanatory power, it's not perfectly suitable for online payment [15]. However, a recent study suggests integrating different models to get a more comprehensive view of achieving the objectives of the research [27]. Therefore, this research will integrate UTAUT with Task technology fit model (TTF) and Initial trust model (ITM). The final model is shown in Figure 2.

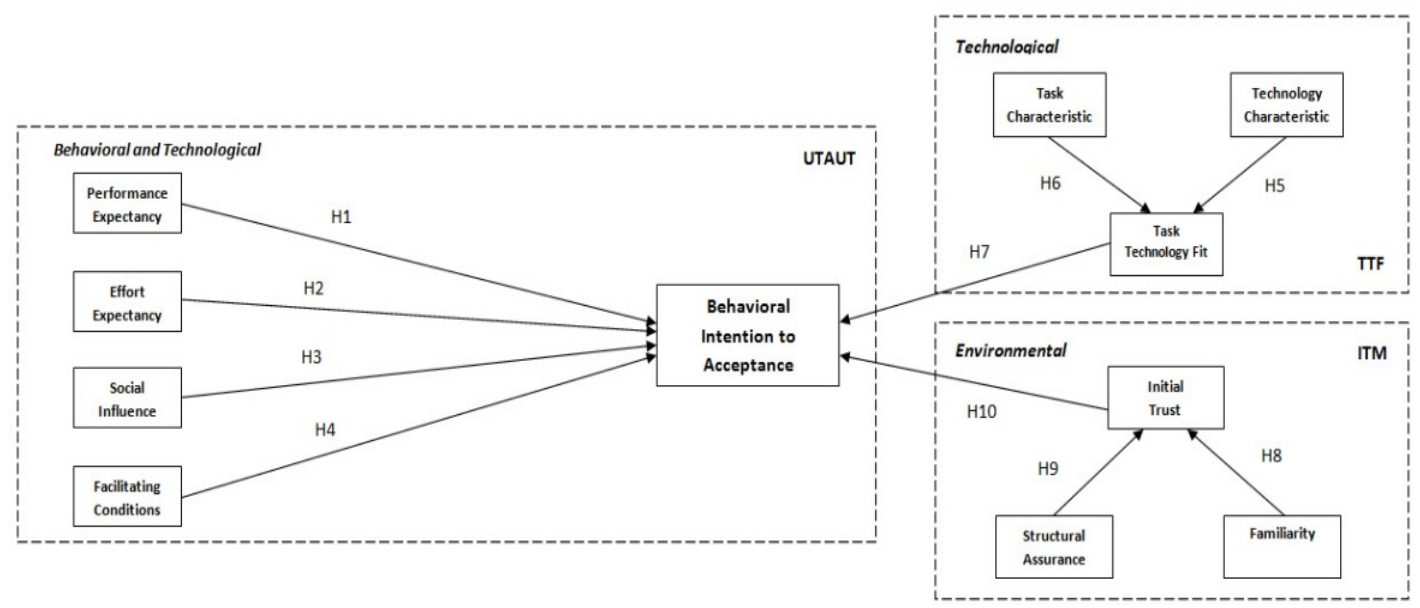

Fig. 2: Conceptual Framework 
Based on the original UTAUT model, the factors performance expectancy (PE), effort expectancy (EE), social influence (SI) and facilitating conditions (FC) will be applicable to find the acceptance of national e-Payment users in Thailand. However, age, gender and experience were not applicable in the model because national e-Payment in Thailand is a new technology that the government is trying to push. Users do not have experience in the use of this system.

Performance expectancy (PE) reflects the recognition of the benefits that will improve performance by using national e-payment such as usefulness, convenient payment, efficiency payment and fast response. Effort expectancy (EE) is defined as perceived ease of using it and reflects user perceptions of how difficult it is to use a national e-payment system such as ease of use, ease of learning and ease of understanding [21]. Social influence (SI) reflects the impact of environmental factors, such as the friend of a user's peers, which affects user behavior [31]. Facilitating conditions (FC) reflect the effect of a user's knowledge, ability and resources [8]. With regards to behavioral intention (BI) linked to acceptance such as intentions to use the system, to manage the account, to transfer [26]. Jansorn et al. [32] found that Performance expectancy (PE), Effort expectancy (EE), Social influence (SI) and Facilitating conditions (FC) have significant impact in the study of acceptance factors for electronic payment services. Therefore this research hypothesized the following:

H1: Performance expectancy positively affects user's intention to accept national e-payment.

H2: Effort expectancy positively affects user's intention to accept national e-payment.

H3: Social influence positively affects user's intention to accept national e-payment.

H4: Facilitating conditions positively affect user's intention to accept national e-payment.

An integration with TTF model such as appropriate service, suitable service and enough service include task characteristics (TAC) that are defined as some of the key aspects of the requirements of users including account management tasks (such as manage account and transfer anytime anywhere). Technology characteristics (TC) are defined as some key aspects of e-payment technology including ubiquity, immediacy, and security of money transfer and remittance, and real-time account information inquiry [21]. He et al. [33] found that system characteristics have significant effects on behavior and intention in the study of decision factors for the adoption of an online payment system by customers. Therefore this research hypothesized the following:

H5: Task technology fit is positively influenced by technology characteristics of national e-payment.

H6: Task technology fit is positively influenced by task characteristics of national e-payment.

H7: Task technology fit positively affects user's intention to accept national e-payment.

In terms of trust ITM such as a dependable system, secure system and reliable system [26].include perceptions of familiarity with the bank (FB) the knowledge of the vendor and an understanding of its relevant procedures and technology [34]. Structural assurances (SA) refer to the safety nets such as legal resources, guarantees and regulations existing in a specific context [35]. Gholami et al. [36] found that trust has significant effects on behavior and intention in the study of factors affecting e-Payment adoption in Nigeria. Therefore this research hypothesized the following:

H8: Familiarity facilitates the initial trust of national e-payment.

H9: Structural assurance facilitates the initial trust of national e-payment.

H10: Initial trust positively influences the user's intention to accept national e-payment.

\section{Conclusion}

This study builds a proposed model of national e-Payment acceptance in Thailand based on UTAUT Integrated with TTF model and ITM. The final result of this study is to create an effective structural model that can explore the national e-Payment acceptance. In addition, this research will collect data from people in Thailand through questionnaires to investigate the determinants of the research model. This model will provide a useful tool to understand and predict user's intention to accept national e-payment in Thailand. 


\section{References}

[1] American University Washington D.C. (2016). What is E-Payment. [Online]. Available: wwwl.american.edu/initeb/sm4801a/epayments.htm

[2] J. Summers. Payment Systems: Design, Governance and Oversight. Central Banking Publications Ltd. 2012: 3.

[3] Biago Bossone, and Massimo Cirasino. The Oversight of the Payment Systems: A Framework for the Development and Governance of Payment Systems in Emerging Economies. The World Bank. May 2001: 7.

[4] Ministry of Finance (2016). National e-Payment. [Online]. Available: http://www.epayment.go.th

[5] Chung-Hung Tsai, Dauw-Song Zhu, and Yueh-Meei Jang. A study on the consumer adoption behaviors of Internet banks. Proc. of Computer and Information Science (ICIS). Niigata. 2013, pp. 263-268.

[6] Dishaw, M. T., and Strong, D. M. Extending the technology acceptance model with task-technology fit constructs. Information \& Management. 1999, 36: 9-21.

[7] F. Davis. A technology acceptance model for empirically testing new end-user information systems: theory and results. Unpublished Ph.D. dissertation, MIT Sloan School of Management. Cambridge. MA. 1985.

[8] V. Venkatesh, et al. User acceptance of information technology: Toward a unified view. MIS Quarterly. 2003, 27: 425-478.

[9] Osden Jokonya. Validating Technology Acceptance Model (TAM) during IT Adoption in Organizations. Proc. of Cloud Computing Technology and Science (CloudCom). Luxembourg. 2016, pp. 509-516.

[10] Shujen Lee Chang and James K. Chen. 3D bio-printing in medical treatment: A technology acceptance model. Proc. of Management of Engineering and Technology (PICMET). Portland. 2016, pp. 3149-3154.

[11] Mohamed Alloghani, Abir Hussain, and Dhiya Al-Jumeily. Technology Acceptance Model for the Use of MHealth Services among Health Related Users in UAE. Proc. of Developments of E-Systems Engineering (DeSE) Dubai. 2015, pp. 213-217.

[12] Shu-Chiang Lin, Satria Fadil Persada, and Reny Nadlifatin. A study of student behavior in accepting the Blackboard Learning System: A Technology Acceptance Model (TAM) approach. Proc. of Developments of ESystems Engineering (DeSE). Paphos. 2014, pp. 457-462.

[13] Zatul Amilah Shaffiei, Mudiana Mokhsin, and Saidatul Rahah Hamidi. A study of user's acceptance and perception towards Campus Management System (CMS) using Technology Acceptance Model (TAM). Proc. of Engineering Education (ICEED). Kuala Lumpur. 2011, pp. 128-131.

[14] Peng Hongxia, Xu Xianhao, and Liu Weidan. Drivers and barriers in the acceptance of mobile payment in China. Proc. of E-Business and E-Government (ICEE), 2011.

[15] Cong Yin, and Lidan Shi. An Empirical Study on Users' Online Payment Behavior of Tourism Website. Proc. of e-Business Engineering (ICEBE). Beijing. 2015, pp. 214-219.

[16] Sheng-Chin Yu, Chia-jen Ting, and Hsing-Chuan Lu. Older-users' acceptance of smartcard payment systems: An investigation of an old-street venders. Proc. of Information Science and Digital Content Technology (ICIDT). Jeju. 2012, pp. 551-556.

[17] Yeoh Sok Foon, and Benjamin Chan Yin Fah. Internet Banking Adoption in Kuala Lumpur: An Application of UTAUT Model. International Journal of Business and Management. 2011, 36 (4): 161-167.

[18] Joel Järvinen, Roope Ohtonen, and Heikki Karjaluoto. Consumer Acceptance and Use of Instagram. Proc. of System Sciences (HICSS). Kauai. 2016, pp. 2227-2236.

[19] Goodhue D. L., and Thompson R. L.. Task-technology fit and individual performance. MIS Quarterly. 2003, 19: 213-236.

[20] Junglas I., Abraham C., and Watson R. T.. Task-technology fit for mobile locatable information systems. Decision Support Systems. 2008, 45: 1046-1057.

[21] Tao Zhou, Yaobin Lu, and Bin Wang. Integrating TTF and UTAUT to explain mobile banking user adoption. Computers in Human Behavior. 2010, 26(4): 760-767.

[22] Alireza Dahghan, Mohammad Amin Moragheb, and Bahareh Baziyar. Using the UTAUT and TTF Models For Acceptance of Mobile Tourism. International Journal of Basic Sciences \& Applied Research. 2014, 3: 101-107. 
[23] Lee C. C., Cheng H. K., and Cheng H. H.. An empirical study of mobile commerce in insurance industry: Tasktechnology fit and individual differences. Decision Support Systems. 2007, 43: 95-110.

[24] Kim K.K. and Prabhakar B.. Initial trust and the adoption of B2C e-commerce: the case of internet banking. ACM SIGMIS Database. 2004, 35: 50-64.

[25] Chen Y.H., and Corkindale D.. Towards an understanding of the behavioral intention to use online news services: an exploratory study. Internet Res. 2008, 18: 286-312.

[26] Kim G., Shin B., and Lee H.G.. Understanding dynamics between initial trust and usage intentions of mobile banking. Information Systems Journal. 2009, 19:283-311.

[27] Jie Gu, Heng Xu, and An'an Hu. Exploring the effect of permission notice on users' initial trust to an application store: The case of China's Android application market. International Conference on Intelligence and Security Informatics (ISI). 2015: 67-72.

[28] Aries Susanto, and Younghoon Chang. Determinants of initial trust formation in electronic commerce acceptance in Indonesia. Proc. of Systems, Process and Control (ICSPC). Kuala Lumpur. 2014, pp. 96-100.

[29] Tiago Oliveiraa, Miguel Fariaa, Manoj Abraham Thomasb, and Aleš Popoviča. Extending the understanding of mobile banking adoption: When UTAUT meets TTF and ITM. International Journal of Information Management. 2014, 34(5): 689-703.

[30] Sahar Afshana, and Arshian Sharifb. Acceptance of mobile banking framework in Pakistan. Telematics and Informatics. 2016, 33(2): 370-387.

[31] Lopez-Nicolas C., Molina-Castillo F. J., and Bouwman H.. An assessment of advanced mobile services acceptance: Contributions from TAM and diffusion theory models. Information \& Management. 2008, 45(6): 359-364.

[32] Teerapat Jansorn, Supaporn Kiattisin and Adisorn Leelasantitham. Study of acceptance factors for electronic payment services. ISS \& MLB. 2013: 452-461.

[33] He Fang, and Mykytyn Peter P.. Decision Factors for the Adoption of an Online Payment System by Customers. International Journal of E-Business Research. 2007, 3(4): 1-32.

[34] Gefen D.. E-commerce: The role of familiarity and trust. Omega. 2000, 28(6): 725-737.

[35] Gefen D., Straub D.W., and Boudreau M.C.. Structural equation modelling and regression: guidelines for research practice. Commun. Assoc. Inf. Syst. 2003, 4: 1-70, 2003.

[36] Roya Gholami, Ugustine Ogun, Elizabeth Koh, John Lim. Factors Affecting e-Payment Adoption in Nigeria. Journal of Electronic Commerce in Organizations. 2010, 8(4): 51-67. 